\title{
Metabolic syndrome and parental history of cardiovascular disease in young adults in urban Ghana
}

Kwame Yeboah ${ }^{1 *}$ D, Kennedy Konlan Dodam', Patrick Kormla Affrim², Linda Adu-Gyamfi ${ }^{3}$, Anormah Rashid Bado ${ }^{1}$, Richard N. A. Owusu Mensah", Afua Bontu Adjei and Ben Gyan ${ }^{4}$

\begin{abstract}
Background: Metabolic syndrome (MetS) in young adults poses significant cardiovascular diseases (CVD) risk for later years. Parental history of CVDs is known to affect the prevalence of CVD risk in adulthood. In sub-Saharan Africa, the burden of MetS in young adults and its relationship with parental CVDs is largely unknown. We studied the gender-specific prevalence of MetS and its association with parental history of diabetes, hypertension and CVDs in young adults resident in urban Ghana.
\end{abstract}

Methods: In a cross-sectional design, 364 young adults aged 20-30 years were randomly recruited from students of University of Ghana. A structured questionnaire was used to collect data on demography, lifestyle, medical and parental medical history. Anthropometric indices and blood pressures were measured. Fasting blood samples were collected to measure plasma levels of glucose, lipid profile, urea and creatinine. MetS was defined according to the Joint Scientific Statement criteria.

Results: The prevalence of MetS was 12.4\%, higher in females than male participants (18.4\% vs 5.7, $p=0.019$ ). Female participants had higher levels of all the components of MetS than the male participants. Compared to participants with no history of parental CVDs, participants with parental CVDs had a higher proportion of abdominal obesity. A positive history of parental CVDs was associated with increase in odds of MetS [OR (95\% Cl): $1.23(1.12-3.04), p=0.037]$.

Conclusion: In our study population, there is relatively high prevalence of MetS; higher in females compared to male participants. Parental history of CVDs was associated with MetS.

\section{Background}

Recent studies from Ghana and other sub-Saharan African countries indicate that the prevalence of cardiovascular diseases (CVDs) is increasing at an alarming rate $[1,2]$. A recent meta-analysis reported that CVDs in sub-Saharan Africa cause a million deaths, constituting $38.3 \%$ of non-communicable disease deaths, and $11.3 \%$ of deaths from all causes [3]. CVDs are associated with constellation of cardio-metabolic risk factors including dyslipidaemia, hypertension, hyperglycaemia and central obesity, generally referred to as Metabolic syndrome (MetS) [4]. Several studies have reported the prevalence

\footnotetext{
* Correspondence: kyeboah@ug.edu.gh; melvinky@gmail.com 1 Department of Physiology, School of Biomedical \& Allied Health Sciences, University of Ghana, P O Box 143, Korle-Bu, Accra, Ghana

Full list of author information is available at the end of the article
}

of MetS in adults from general and diseased populations in sub-Saharan Africa. The prevalence of the MetS in urbanised sub-Sahara African population ranges from $11 \%$ in Benin [5] to $34.6 \%$ in Kenya [6]. In most studies, the prevalence of MetS varies with gender, age, ethnicity and geographical location. MetS in young adulthood is a strong predictor of future CVDs [7, 8], and reversing components of MetS may be protective against CVDs in adulthood [9]. This observation suggests that early screening and treatment of components MetS may be beneficial in the amelioration of the complications associated with this syndrome. However, there is paucity of data on the prevalence of the MetS in young adults in Ghana or other indigenous West African countries. 
Individuals with a positive parental history of CVD, particularly if premature at onset, is a widely accepted risk factor for cardiovascular events. Recent guidelines recommend consideration of a positive parental history of premature coronary heart disease when deciding whether to initiate antihyperlipidemic or antihypertensive therapy for primary prevention. In the Atherosclerosis Risk in Communities study, conducted in middle-aged adults (45-65 years), parental history of diabetes/hypertension in both parents was associated with 8-fold increase in the likelihood of MetS in offspring [10]. It is, however, uncertain how parental history of CVD may affect MetS in young adults in sub-Saharan Africa. The prevalence of MetS varies with gender, and females are more likely to know the CVD history of their parent. In this study, we assessed the gender-specific prevalence of MetS in urban Ghana, and the association of parental history of CVDs on the prevalence of MetS. We hypothesise that, compared to those without parental history of CVDs, young adults from parents with history of CVDs will have higher levels of MetS.

\section{Methods}

\section{Setting, design and population}

The study was a cross-sectional design conducted among young adults in Accra, from November 2015 through May 2016. Accra is the capital of Ghana and is located in the Greater Accra Region. Geographically, Accra is bounded on the north by latitude $541.4 \mathrm{~N}$, on the south by the Gulf of Guinea, on the east by Longitude $0001 \mathrm{E}$ and on the west by Longitude 0021.5 (Fig. 1). According to the Ghana Demographic and Health survey, Accra has the highest prevalence of hypertension in Ghana.
The study participants were male and female young adults within the age range of 20-30 years, recruited from University of Ghana. Potential participants were invited electronically through SherlockMD online application (www.sherlockmd.org). Out of 556 electronic invitations sent, 408 responded favourably, of which 382 met the eligibility criteria. However, 370 participants were able to visit the study centre for clinical measurements and blood sample collection. During analysis, four participants were excluded due to incomplete data. Participants uncertain of their parent's CVD status, and those already diagnosed with diabetes, hypertension, hyperlipidaemia, renal disease, overt cardiovascular disease were excluded from the study. The study was conducted in conformity with the Helsinki Declaration on Human Experimentation, 1964 with subsequent revisions, latest Seoul, October 2008. Institutional approval was granted by the Ethical and Protocol Review Committee of the College of Health Sciences, University of Ghana (MS-ET/M.3-P3.3/2015-2016).

\section{Lifestyle and health data}

After informed consent, a structured questionnaire was used to collect socio-demographic and lifestyle data (age, gender, personal and family medical history, smoking and alcohol intake). A positive parental history of diabetes, hypertension or CVD was documented as responding yes to these questions: "Has your mother/father ever been diagnosed as diabetic or on anti-diabetic drug?" or "Has your mother/father ever been diagnosed as having high BP or on antihypertensive drug?" or "Has your mother/ father ever been diagnosed as having any of the following heart/blood vessel disease or on treatment for this disease?" Parental CVDs (heart/blood vessel disease) were

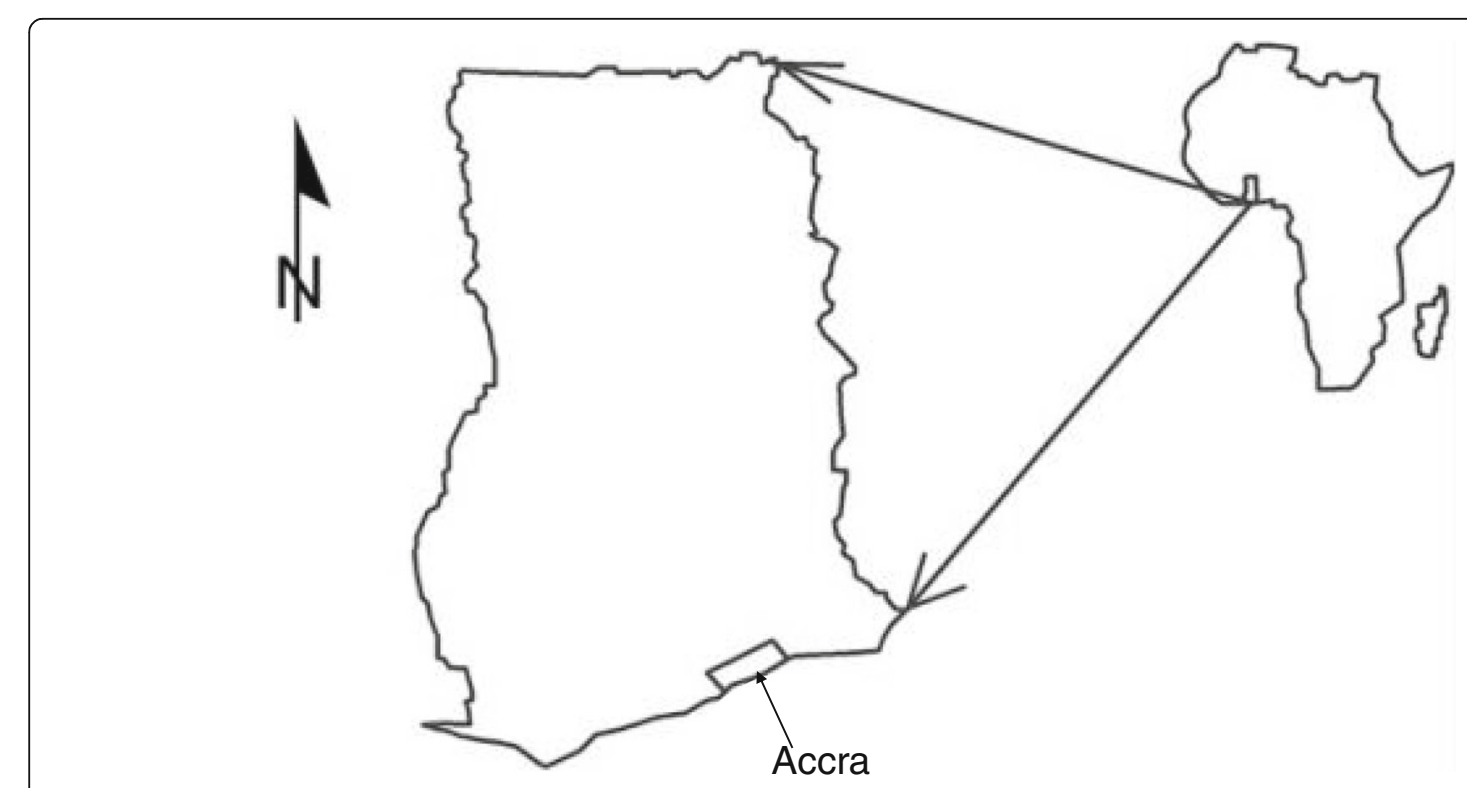

Fig. 1 Map of study location, Accra, Ghana. (Credit: Michael Atta Kyereh, Web Design Ghana) 
defined as either mother or father having one of the following: stroke, angina, heart attack, heart disease, limb amputation that is not through accident and vascular surgery.

\section{Anthropometry and blood pressure}

Weight, height, waist and hip circumferences were measured using standard protocol [11]. Briefly, body weight was determined on twice using a homologated electronic scale (Seca 770) following due calibration (precision $\pm 0.1 \mathrm{~kg}$ ), with the patient wearing light clothing with shoes removed. Height was also measured with a portable system (Seca 222) with the patient shoeless in the upright position. Body mass index (BMI) was computed as weight $(\mathrm{kg})$ divided by height squared $\left(\mathrm{m}^{2}\right)$. Percentage body fat and visceral fat were estimated through bioelectrical impedance analysis with the Body composition monitor (BF- 508, Omron Healthcare, Inc., Vernon Hills, IL, USA). Waist circumference was measured with nonelastic tape measure at the upper border of the iliac crest, parallel to the floor without compressing the skin. Blood pressure (BP) was measured after 5 mins rest, with participant in seated position with a back support, using with automated BP monitor (HEM-705CP; Omron Corporation, Tokyo, Japan). Three different measurements were taken and the last two averaged for analysis.

\section{Biochemical analysis}

After 8-12 h of overnight fasting, approximately $10 \mathrm{ml}$ of venous blood was drawn from the antecubital fossa into appropriate tubes. The samples were centrifuged and the serum/plasma aliquoted for analysis. Fasting plasma glucose (FPG), total cholesterol, high-density (HDL) lipoprotein cholesterol, triglyceride, plasma urea and serum creatinine levels were analysed using chemical autoanalyser (Mindray BS 200, China) and commercial reagents (Randox Laboratory Reagents, UK). Low-density lipoprotein (LDL) cholesterol levels were calculated using Friedewald's formula.

\section{Definition of MetS}

MetS was defined, according to the Joint Scientific Statement criteria [4], as individuals with any three or more of the following five components: (1) abdominal obesity (waist circumference $\geq 94 \mathrm{~cm}$ for men $\& \geq 80 \mathrm{~cm}$ for women); (2) high triglycerides $\geq 1.7 \mathrm{mmol} / \mathrm{L}$; (3) low HDL cholesterol: men $<1.0 \mathrm{mmol} / \mathrm{L}$ or women $<1.3 \mathrm{mmol} / \mathrm{L}$; and (4) High BP (systolic BP $\geq 130 \mathrm{mmHg}$ and/or diastolic $\mathrm{BP} \geq 85 \mathrm{mmHg}$ ); and (5) impaired fasting glucose $\geq 5.6 \mathrm{mmol} / \mathrm{l}$.

\section{Statistical analysis}

The data was analysed using IBM SPSS version 20 software. Gender comparison of anthropometric indices, biochemical analytes, socio-demographic and health variables were performed using student's $t$-test for continuous variables and Pearson's $\chi^{2}$ test for categorical variables. Association between components of MetS and parental diabetes, hypertension and CVDs were analysed as Pearson's $\chi^{2}$, with Fisher adjustment or Yate's continuity correction when appropriate. Univariate and multivariable logistic regression models were used to analyse the change in odds of MetS and parental diabetes, hypertension and CVDs. $p<0.05$ was considered statistically significant.

\section{Results}

The prevalence of MetS in our study participants was $12.4 \%$, higher in females than males. Male participants had higher proportions of current and previous alcohol and smoking status, generally taller with higher waist-hip ratio and serum creatinine levels. Female participants had higher proportions of family history of diabetes, hypertension and CVDs; higher mean levels of BMI, hip circumference, FPG, systolic, diastolic, mean \& pulse BPs (Table 1). The prevalence of components of MetS in our study participants are as follows: high systolic BP 35.6\%, low HDL cholesterol $30.9 \%$, impaired fasting glucose $18.2 \%$, abdominal obesity $17.1 \%$ and hypertriglycerimia $1 \%$. Compared to males, female participants had higher prevalence of abdominal obesity, high BP and low HDL cholesterol (Fig. 2). In addition, female participants had greater accumulation $(\geq 2)$ of components of MetS (Fig. 3).

Abdominal obesity was associated with parental CVDs, diabetes and hypertension in the entire study participants. In male participants, parental history of CVDs was associated with low HDL cholesterol. In females, low HDL cholesterol level was associated with parental history of CVDs, diabetes and hypertension. Also, high BP and impaired fasting glucose were associated with parental diabetes (Table 2). In the entire study participants, parental diabetes, hypertension and CVDs were associated increased change in odds of MetS in unadjusted logistic regression models. After adjustment for various risk factors, only parental CVDs was associated with increased change in odds of MetS. In female participants, parental history of diabetes, hypertension and CVDs were associated with increased in odds of MetS in unadjusted logistic regression models. After adjustment for confounders, the association between MetS and parental hypertension and CVDs still remained significant. MetS in male participants was not associated with parental history of diabetes, hypertension and CVDs (Table 3).

\section{Discussion}

The prevalence of MetS in this study, conducted in young adults in urban Ghana, is $12.4 \%$, higher in females 
Table 1 General characteristics of study participants by gender

\begin{tabular}{|c|c|c|c|c|}
\hline & All participants $(n=364)$ & Males $(n=174)$ & Females $(n=190)$ & $p$ \\
\hline Age, years & $24.9 \pm 2.9$ & $25 \pm 2.7$ & $24.7 \pm 3.1$ & 0.569 \\
\hline \multicolumn{5}{|l|}{ Smoking status, n (\%) } \\
\hline Current & $26(7.1)$ & $23(13.2)$ & $3(1.6)$ & $<0.001$ \\
\hline Former & $39(10.7)$ & $32(18.4)$ & $7(3.7)$ & 0.03 \\
\hline Never & $299(82.1)$ & $119(68.4)$ & $180(94.7)$ & 0.74 \\
\hline \multicolumn{5}{|l|}{ Alcohol status, n (\%) } \\
\hline Current & $77(21.1)$ & $59(33.9)$ & $18(9.5)$ & $<0.001$ \\
\hline Former & $87(23.9)$ & $67(38.5)$ & $20(10.5)$ & 0.03 \\
\hline Never & $200(54.9)$ & $48(27.6)$ & $152(80)$ & $<0.001$ \\
\hline \multicolumn{5}{|c|}{ Parental history of CVDs, n (\%) } \\
\hline Diabetes & $60(16.5)$ & $23(13.2)$ & $37(19.5)$ & 0.032 \\
\hline Hypertension & $74(20.3)$ & $26(15)$ & $48(25.3)$ & 0.017 \\
\hline Cardiovascular diseases & $90(24.7)$ & $16(9.2)$ & $74(38.9)$ & $<0.001$ \\
\hline Weight, kg & $69.2 \pm 9.9$ & $68.1 \pm 8.9$ & $70.1 \pm 10.7$ & 0.054 \\
\hline Height, cm & $167 \pm 7$ & $168 \pm 7$ & $166 \pm 6$ & $<0.001$ \\
\hline $\mathrm{BMI}, \mathrm{kg} / \mathrm{m}^{2}$ & $24.9 \pm 3.8$ & $24.1 \pm 3.3$ & $25.6 \pm 4$ & $<0.001$ \\
\hline Waist circumference, cm & $88 \pm 16$ & $89 \pm 16$ & $86 \pm 17$ & 0.135 \\
\hline Hip circumference, cm & $98 \pm 16$ & $96 \pm 16$ & $99 \pm 15$ & 0.025 \\
\hline Waist-hip ratio & $0.91 \pm 0.19$ & $0.94 \pm 0.2$ & $0.88 \pm 0.18$ & 0.002 \\
\hline Body fat, $\%$ & $26.7 \pm 8.7$ & $25.2 \pm 7.6$ & $28.1 \pm 9.3$ & 0.001 \\
\hline Visceral fat, \% & $5.6 \pm 3.7$ & $5.3 \pm 3.5$ & $4.6 \pm 0.9$ & 0.115 \\
\hline Systolic BP, mmHg & $116 \pm 12$ & $113 \pm 11$ & $119 \pm 13$ & $<0.001$ \\
\hline Diastolic BP, mmHg & $75 \pm 9$ & $74 \pm 8$ & $76 \pm 10$ & 0.002 \\
\hline Pulse $B P, \mathrm{mmHg}$ & $41 \pm 8$ & $40 \pm 8$ & $42 \pm 8$ & $<0.001$ \\
\hline Mean $\mathrm{BP}, \mathrm{mmHg}$ & $89 \pm 9$ & $87 \pm 8$ & $91 \pm 10$ & $<0.001$ \\
\hline $\mathrm{FPG}, \mathrm{mmol} / \mathrm{l}$ & $4.9 \pm 1.1$ & $4.6 \pm 0.9$ & $5.2 \pm 1.3$ & $<0.001$ \\
\hline Triglycerides, mmol/l & $1.5 \pm 0.4$ & $1.5 \pm 0.4$ & $1.6 \pm 0.4$ & 0.082 \\
\hline Total cholesterol, mmol// & $5.2 \pm 1.1$ & $5.2 \pm 1.2$ & $5.1 \pm 1$ & 0.389 \\
\hline HDL cholesterol, mmol/l & $1.1 \pm 0.5$ & $1.1 \pm 0.4$ & $1.1 \pm 0.5$ & 0.877 \\
\hline LDL cholesterol, mmol/l & $3.6 \pm 1.3$ & $3.6 \pm 1.3$ & $3.6 \pm 1.3$ & 0.944 \\
\hline vLDL cholesterol, mmol// & $0.35 \pm 0.15$ & $0.34 \pm 0.13$ & $0.35 \pm 0.17$ & 0.505 \\
\hline Urea, mmol// & $3.4 \pm 0.8$ & $3.5 \pm 0.9$ & $3.4 \pm 0.8$ & 0.197 \\
\hline Creatinine, mmol/l & $91 \pm 16$ & $94.8 \pm 17.9$ & $88.5 \pm 14.5$ & 0.001 \\
\hline Metabolic syndrome, \% & $45(12.4)$ & $10(5.7)$ & $35(18.4)$ & 0.019 \\
\hline
\end{tabular}

CVDs cardiovascular diseases, BMI body mass index, BP blood pressure, FPG fasting plasma glucose, $H D L$ high density lipoprotein, $L D L$ low density lipoprotein, $v L D L$ very low density lipoprotein

than male participants. Because the hypothesis being tested requires knowledge of parental diabetes, hypertension and CVDs status, tertiary student were suited as participants in this study. It should, however, be noted that, the prevalence of high BP and obesity in our study were similar to what was reported in non-tertiary young adults from poor neighbourhood in Accra [12]. This indicate an alarming rate of high BP in young adults in urban Ghana.
From our literature search, this is the first study to report MetS in young adults resident in West Africa. Studies reports from western nations have pegged the prevalence of MetS in young adults within the range similar to our findings. For instance, the in the United States, the National Health and Nutrition Examination Survey (NHANES) III reported the prevalence of MetS in young adults aged $20-29$ years to be $6.7 \%$ [13], the Bogalusa Heart Study [14] reported $13 \%$ and the 


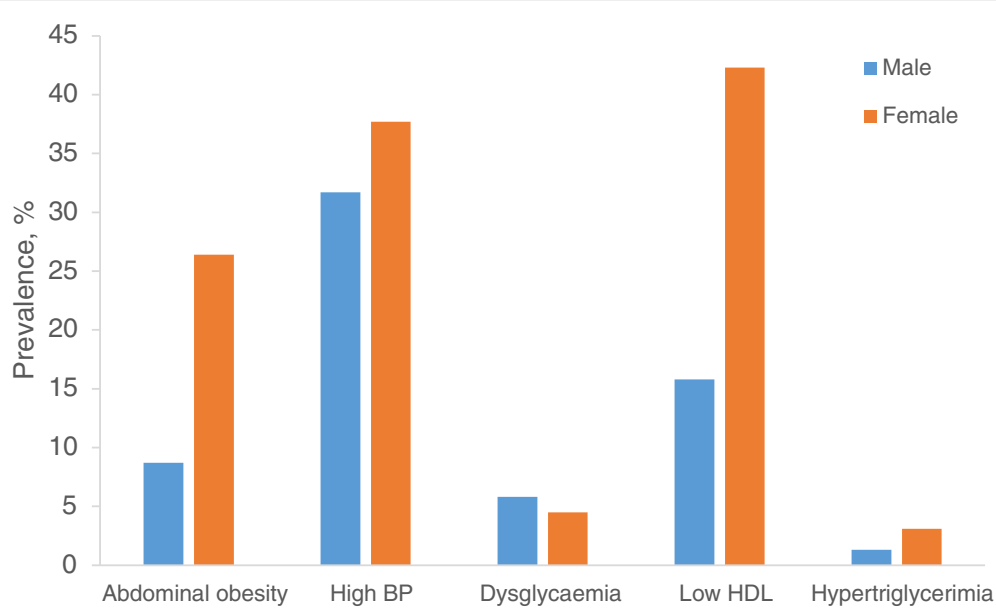

Fig. 2 Gender-specific prevalence of components of metabolic syndrome. Data were analyzed using Pearson's $x^{2}$ with Fisher adjustment or Yate's corrections when appropriate. Compared to male participants, female participants had higher prevalence of abdominal obesity $(8.7 \%$ vs $26.4 \%$, $p=0.002)$, low HDL $(15.8 \%$ vs $42.3 \%, p<0.001)$

NHANES III depression study [15] reported 7.8\%. In Europe, studies conducted in Finland [16] and Northern Ireland [17] reported prevalence to be 5.8 and $10.6 \%$ respectively. Studies conducted in developing countries such as Turkey [18] and Jamaica [19] reported prevalence of MetS in young adults to be 3.6 and $1.2 \%$ respectively. The studies above reported inconsistencies in gender-specific prevalence in MetS. Similar to our findings, female participants had a higher prevalence of MetS in Jamaica and Turkey studies $[18,19]$. The Bogalusa and Irish studies reported similar prevalence among male and female participants [14, 17], while the NHANES and Finish studies reported higher prevalence in male participants $[13,16]$. The prominent components of MetS in our study were high BP, low HDL cholesterol and abdominal obesity. These components were common in female participants than males participants, similar to what was reported in Turkish study [18]. In Jamaican young adults, compared to female participants, male participants had higher proportion of high BP, lower proportion of abdominal obesity and low HDL cholesterol [19].

Systematic review and meta-analysis have demonstrated that presence of MetS is associated with a twofold increase in composite CVD, stroke, myocardial infarction and all-cause mortality [20]. The risk of CVD mortality associated with MetS is greater than the risk

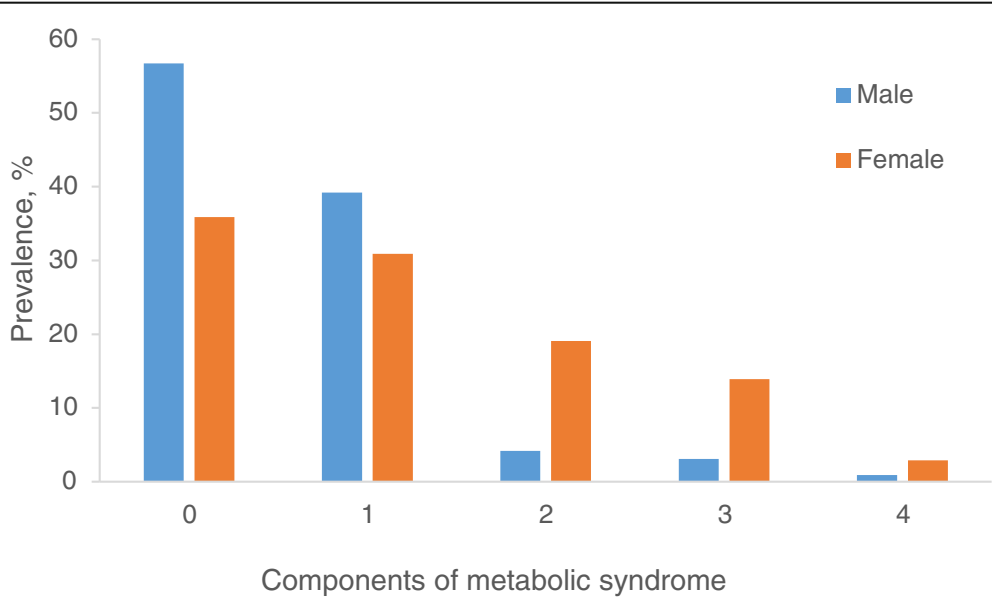

Fig. 3 Number of components of metabolic syndrome by gender. Data were analyzed using Pearson's $x^{2}$ with Fisher adjustment or Yate's corrections when appropriate. Compared to females, greater proportion of males were without any components metabolic syndrome (56.7\% vs $35.9 \%, p=0.003)$. Compared to males, greater proportion of females had two $(19.1 \%$ vs $4.2 \%, p<0.001)$ or three $(13.9 \%$ vs $3.1 \%, p=0.005)$ components of metabolic syndrome 
Table 2 Components of metabolic syndrome and parental CVDs, diabetes and hypertension

\begin{tabular}{|c|c|c|c|c|c|c|c|c|c|}
\hline & \multicolumn{3}{|c|}{ Parental CVDs } & \multicolumn{3}{|c|}{ Parental diabetes } & \multicolumn{3}{|c|}{ Parental hypertension } \\
\hline & Absent & Present & $p$ & Absent & Present & $p$ & Absent & Present & $p$ \\
\hline \multicolumn{10}{|l|}{ All participants $(n=364)$} \\
\hline High BP & $95(34.8)$ & $35(39.1)$ & 0.469 & $106(34.8)$ & $23(38.7)$ & 0.608 & $101(34.7)$ & $29(39.3)$ & 0.485 \\
\hline Low HDL & $81(29.7)$ & $32(35.9)$ & 0.286 & $90(29.7)$ & $22(37.1)$ & 0.279 & $86(29.6)$ & $28(37.7)$ & 0.175 \\
\hline Abdominal obesity & $42(15.2)$ & $23(25)$ & 0.028 & $46(15.2)$ & $16(25.8)$ & 0.298 & $44(15.2)$ & $19(26.2)$ & 0.033 \\
\hline IFG & $50(18.1)$ & $17(18.8)$ & 0.914 & $55(18.1)$ & $12(19.4)$ & 0.727 & $53(18.4)$ & $13(18)$ & 0.887 \\
\hline Hypertriglycerimia & $1(1.1)$ & $3(3.6)$ & 0.059 & $0(0)$ & $0(0)$ & & $0(0)$ & $0(0)$ & \\
\hline \multicolumn{10}{|l|}{ Males $(n=174)$} \\
\hline High BP & $37(23.4)$ & $5(31.3)$ & 0.485 & $41(27.2)$ & $6(16.2)$ & 0.915 & $21(14.2)$ & $7(26.9)$ & 0.1 \\
\hline Low HDL & $9(6)$ & $5(31.3)$ & 0.001 & $11(7.3)$ & $3(8.1)$ & 0.344 & $14(9.5)$ & $2(7.7)$ & 0.774 \\
\hline IFG & $18(11.4)$ & $3(18.8)$ & 0.389 & $15(9.9)$ & $2(5.4)$ & 0.852 & $11(7.4)$ & $4(15.4)$ & 0.183 \\
\hline \multicolumn{10}{|l|}{ Females $(n=190)$} \\
\hline High BP & $58(50)$ & $30(40.5)$ & 0.202 & $41(27)$ & $17(45.9)$ & 0.023 & $62(43.7)$ & $22(45.8)$ & 0.793 \\
\hline Low HDL & $72(62.1)$ & $28(37.8)$ & 0.001 & $27(17.6)$ & $19(51.4)$ & $<0.001$ & $30(21.1)$ & $26(54.2)$ & $<0.001$ \\
\hline Abdominal obesity & $42(36.2)$ & $23(31.1)$ & 0.468 & $46(15.2)$ & $16(25.8)$ & 0.125 & $53(18.4)$ & $13(18)$ & 0.198 \\
\hline IFG & $32(27.6)$ & $14(18.9)$ & 0.174 & $21(13.7)$ & $10(27)$ & 0.049 & $17(12)$ & $9(18.8)$ & 0.238 \\
\hline
\end{tabular}

Data were analyzed as Pearson's $x^{2}$ with Fisher adjustment or Yate's corrections when appropriate

$B P$ blood pressure, HDL low density lipoprotein cholesterol, IFG impaired fasting glucose

associated with individual components of MetS, suggesting that individuals with the constellation of metabolic abnormalities that characterise MetS should be targeted for aggressive primary prevention. It has also been shown that development of components of MetS in childhood can be tracked into adolescence and adulthood [21], emphasising the essence of early screening of MetS in CVD prevention [22]. Additionally, the commonest components of MetS in our study, increased BP and dyslipidemia, have been shown to be strong predictors of vascular events [23].
The findings of this study indicate that abdominal obesity was associated with parental CVDs, diabetes and hypertension in all participants. A positive parental history of CVDs was associated with increase in the likelihood of MetS in offspring after adjustment for confounders. Parental history of CVD may reflect the genetic, biochemical, and behavioural factors which may predispose an individual to a higher risk of CVD [24]. In the Family Heart study, family history of obesity, diabetes and hypertension were associated with MetS [25]. In female participants in the current study, low HDL cholesterol was associated

Table 3 Logistic regression models of metabolic syndrome versus parental diabetes, hypertension and CVDs

\begin{tabular}{|c|c|c|c|c|}
\hline & Unadjusted OR (95\% Cl) & $p$ & Adjusted OR $(95 \% \mathrm{Cl})^{\mathrm{a}}$ & $p$ \\
\hline \multicolumn{5}{|l|}{ All participants } \\
\hline Parental diabetes & $1.14(1.09-2.06)$ & 0.031 & $1.01(0.89-3.87)$ & 0.152 \\
\hline Parental hypertension & $1.61(1.17-2.94)$ & 0.018 & $1.18(1.01-2.12)$ & 0.054 \\
\hline Parental CVDs & $2.11(1.41-4.76)$ & $<0.001$ & $1.23(1.12-3.04)$ & 0.037 \\
\hline \multicolumn{5}{|l|}{ Males } \\
\hline Parental diabetes & $2.36(0.54-4.12)$ & 0.487 & $1.41(0.31-8.91)$ & 0.561 \\
\hline Parental hypertension & $2.81(0.72-5.62)$ & 0.238 & $1.87(0.81-7.02)$ & 0.421 \\
\hline Parental CVDs & $1.59(0.62-3.11)$ & 0.204 & $1.92(0.51-3.68)$ & 0.384 \\
\hline \multicolumn{5}{|l|}{ Females } \\
\hline Parental diabetes & $1.32(1.11-2.65)$ & $<0.001$ & $1.17(0.94-2.97)$ & 0.091 \\
\hline Parental hypertension & $2.01(1.12-3.14)$ & $<0.001$ & $1.41(1.07-2.85)$ & 0.026 \\
\hline Parental CVDs & $2.24(1.08-5.01)$ & $<0.001$ & $1.51(1.14-4.52)$ & 0.017 \\
\hline
\end{tabular}

Data analyzed using binary logistic regression for unadjusted odds ratio and multivariable regression for adjusted odds ratio OR odds ratio, CVDs cardiovascular diseases

adjusted for age, gender, alcohol intake and smoking status 
with parental diabetes, hypertension and CVDs. Also, high BP and dysglycaemia were associated with parental diabetes. Similar findings were reported in the Framingham Heart and Offspring Cohorts study, in which there was association in systolic BP, plasma total cholesterol, HDL cholesterol and BMI between parent and offspring, as well as siblings [26]. This indicates that young adults from parents with CVDs should be monitored and treated for MetS to reduce the risk of developing CVDs in the future.

\section{Limitations of the study}

This study was conducted in young adults in urban Ghana, and hence, the findings may differ from periurban and rural population; generalisation cannot be made for the entire Ghanaian population. We cannot infer causation from the findings of the study due to the crosssectional design. The data on parental history of diabetes, hypertension and CVDs may be affected by recall bias, which may lead to misclassification of some study participant. In this study, compared to males, more females reported positive parental history of diabetes, hypertension and CVDs. This might be attributed to gender-based recall bias in the assessment of parental medical history. In Ghana, due to superstitious beliefs attached to chronic diseases like diabetes, hypertension and CVDs [27], many parents may fail to disclose unrecognized disease to close family members, even their children. Young women, however, due to their traditional responsibility of cooking and caring for their aged parents, as well as accompanying them to the hospital and supporting them to adhere to their medications and dietary regimen, are more likely to be aware of their parent's CVD status. Such information bias and the subsequent differential misclassification of parental CVD status may clearly impair the findings of this study.

\section{Conclusion}

In our study population aged between 20 and 29 years, the prevalence of MetS is $12.4 \%$, higher in females than male participants. Parental history of CVDs was associated with MetS, especially in female participants.

\section{Abbreviations \\ BMI: Body mass index; BP: Blood pressure; CVDs: Cardiovascular disease; FPG: Fasting plasma glucose; HDL: High density lipoprotein; LDL: Low density lipoprotein; MetS: Metabolic syndrome}

\section{Acknowledgements}

Our profound appreciation to Mr. Abindau Emmanuel, Ms. Jennifer A. Agyekum, Dr. Owusu Achaw and Mr. Felix Twum who assisted during field work. We also thank Mr. Michael Atta Kyereh for drawing the image for Fig. 1.

\section{Funding}

There was no funding for this study.

\section{Availability of data and materials}

The dataset supporting the conclusion of this study is available for systematic review and meta-analysis upon request.

\section{Authors' contributions}

KY contributed to conception, design, data analysis, drafting the manuscript and bears the primary responsibility for the content of the manuscript. KKD collected the data and revised the manuscript. PK was involved in laboratory analysis and revision of the manuscript. LAG, MA \& RNA were involved in the revision of the manuscript. BG was involved in laboratory analysis and revision of the manuscript. All the authors read and approved the content of the manuscript.

\section{Ethics approval and consent to participate}

The study was conducted in conformity with the Helsinki Declaration on Human Experimentation, 1964 with subsequent revisions, latest Seoul, October 2008. Ethical approval for the study was granted by the Ethics and Protocol Review Committee of the College of Health Science, University of Ghana (Protocol ID number: MS-Et/M.3 - P.3.3/2015-2016). All the participants provided voluntary written consent before recruited into the study.

\section{Consent for publication}

Not applicable

\section{Competing interests}

The authors declare that they have no competing interests.

\section{Publisher's Note}

Springer Nature remains neutral with regard to jurisdictional claims in published maps and institutional affiliations.

\section{Author details}

'Department of Physiology, School of Biomedical \& Allied Health Sciences, University of Ghana, P O Box 143, Korle-Bu, Accra, Ghana. ${ }^{2}$ Department of Chemical Pathology, School of Biomedical \& Allied Health Sciences, University of Ghana, Accra, Ghana. ${ }^{3}$ Department of Medical Biochemistry, School of Biomedical \& Allied Health Sciences, University of Ghana, Accra,

Ghana. ${ }^{4}$ Department of Immunology, Noguchi Memorial Institute for Medical Research, University of Ghana, Accra, Ghana.

Received: 11 May 2017 Accepted: 30 July 2017

Published online: 03 August 2017

\section{References}

1. Yeboah K, Puplampu P, Ainuson J, Akpalu J, Gyan B, Amoah AGB. Peripheral artery disease and exertional leg symptoms in diabetes patients in Ghana. BMC Cardiovasc Disord. 2016:16(1):1-9.

2. Kengne AP, Amoah AG, Mbanya J-C. Cardiovascular complications of diabetes mellitus in sub-Saharan Africa. Circulation. 2005;112(23):3592-601.

3. Moran A, Forouzanfar M, Sampson U, Chugh S, Feigin V, Mensah G. The epidemiology of cardiovascular diseases in sub-Saharan Africa: the global burden of diseases, injuries and risk factors 2010 study. Prog Cardiovasc Dis. 2013:56(3):234-9.

4. Alberti KGMM, Eckel RH, Grundy SM, Zimmet PZ, Cleeman JI, Donato KA, Fruchart J-C, James WPT, Loria CM, Smith SC. Harmonizing the metabolic syndrome. A joint interim statement of the international diabetes federation task force on epidemiology and prevention; National Heart, Lung, and Blood Institute; American Heart Association; world heart federation; international atherosclerosis society; and International Association for the Study of obesity. Circulation. 2009;120(16):1640-5.

5. Ntandou G, Delisle H, Agueh V, Fayomi B. Abdominal obesity explains the positive rural-urban gradient in the prevalence of the metabolic syndrome in Benin, West Africa. Nutr Res. 2009;29(3):180-9.

6. Kaduka LU, Kombe Y, Kenya E, Kuria E, Bore JK, Bukania ZN, Mwangi M. Prevalence of metabolic syndrome among an urban population in Kenya. Diabetes Care. 2012;35(4):887-93.

7. Chen W, Srinivasan SR, Li S, Xu J, Berenson GS. Clustering of long-term trends in metabolic syndrome variables from childhood to adulthood in blacks and WhitesThe Bogalusa heart study. Am J Epidemiol. 2007;166(5): 527-33

8. Chen W, Srinivasan SR, Li S, Xu J, Berenson GS. Metabolic syndrome variables at low levels in childhood are beneficially associated with adulthood cardiovascular risk. The Bogalusa Heart Study. Diabetes Care. 2005;28(1):126-31. 
9. Juonala M, Magnussen CG, Berenson GS, Venn A, Burns TL, Sabin MA, Srinivasan SR, Daniels SR, Davis PH, Chen W, et al. Childhood adiposity, adult adiposity, and cardiovascular risk factors. N Engl J Med. 2011;365(20):1876-85.

10. Liese AD, Mayer-Davis EJ, Tyroler HA, Davis CE, Keil U, Schmidt Ml, Brancati FL, Heiss G. Familial components of the multiple metabolic syndrome: the ARIC study. Diabetologia. 1997;40(8):963-70.

11. World Health Organization. Waist circumference and waist-hip ratio: report of a WHO expert consultation. In: 8-11 December 20082011. Geneva: WHO; 2011.

12. Afrifa-Anane E, Agyemang C, SNA C, Ogedegbe G, de-Graft Aikins A. The association of physical activity, body mass index and the blood pressure levels among urban poor youth in Accra, Ghana. BMC Public Health. 2015; 15(1):269.

13. Ford ES, Giles WH, Dietz WH. Prevalence of the metabolic syndrome among us adults: findings from the third national health and nutrition examination survey. JAMA. 2002;287(3):356-9.

14. Tzou WS, Douglas PS, Srinivasan SR, Bond MG, Tang R, Chen W, Berenson GS, Stein JH. Increased subclinical atherosclerosis in young adults with metabolic syndrome: the Bogalusa heart study. J Am Coll Cardiol. 2005; 46(3):457-63.

15. Kinder LS, Carnethon MR, Palaniappan LP, King AC, Fortmann SP. Depression and the metabolic syndrome in young adults: findings from the third National Health and nutrition examination survey. Psychosom Med. 2004;66(3):316-22.

16. Herva A, Räsänen P, Miettunen J, Timonen M, Läksy K, Veijola J, Laitinen J, Ruokonen A, Joukamaa M. Co-occurrence of metabolic syndrome with depression and anxiety in young adults: the northern Finland 1966 birth cohort study. Psychosom Med. 2006;68(2):213-6.

17. Ferreira I, Boreham CA, Twisk JW, Gallagher AM, Young IS, Murray LJ, Stehouwer CD. Clustering of metabolic syndrome risk factors and arterial stiffness in young adults: the Northern Ireland young hearts project. J Hypertens. 2007;25(5):1009-20.

18. Soysal A, Demiral Y, Soysal D, Uçku R, Köseoğlu M, Aksakoğlu G. The prevalence of metabolic syndrome among young adults in Izmir, Turkey. Anadolu Kardiyol Derg. 2005;5(3):196-201.

19. Ferguson TS, Tulloch-Reid MK, Younger NO, Knight-Madden JM, SammsVaughan M, Ashley D, Van den Broeck J, Wilks RJ. Prevalence of the metabolic syndrome and its components in relation to socioeconomic status among Jamaican young adults: a cross-sectional study. BMC Public Health. 2010:10(1):307.

20. Mottillo S, Filion KB, Genest J, Joseph L, Pilote L, Poirier P, Rinfret S, Schiffrin $\mathrm{EL}$, Eisenberg MJ. The metabolic syndrome and cardiovascular risk: a systematic review and meta-analysis. J Am Coll Cardiol. 2010;56(14):1113-32.

21. Katzmarzyk PT, Pérusse L, Malina RM, Bergeron J, Després J-P, Bouchard C. Stability of indicators of the metabolic syndrome from childhood and adolescence to young adulthood: the Québec family study. J Clin Epidemiol. 2001;54(2):190-5.

22. Morrison JA, Friedman LA, Gray-McGuire C. Metabolic syndrome in childhood predicts adult cardiovascular disease 25 years later: the Princeton lipid research clinics follow-up study. Pediatrics. 2007;120(2):340-5.

23. Dekker JM, Girman C, Rhodes T, Nijpels G, Stehouwer CDA, Bouter LM Heine RJ. Metabolic syndrome and 10-year cardiovascular disease risk in the Hoorn study. Circulation. 2005;112(5):666-73.

24. Hong Y, Pedersen NL, Brismar K, de Faire U. Genetic and environmental architecture of the features of the insulin-resistance syndrome. Am J Hum Genet. 1997;60(1):143-52

25. Hunt KJ, Heiss G, Sholinsky PD, Province MA. Familial history of metabolic disorders and the multiple metabolic syndrome: the NHLBI family heart study. Genet Epidemiol. 2000;19(4):395-409.

26. Lee KE, Klein BE, Klein R. Familial aggregation of components of the multiple metabolic syndrome in the Framingham heart and offspring cohorts: genetic analysis workshop problem 1. BMC Genet. 2003;4(1):S94.

27. Aikins A-G. Ghana's neglected chronic disease epidemic: a developmental challenge. Ghana Med J. 2007;41(4):154.

\section{Submit your next manuscript to BioMed Central and we will help you at every step:}

- We accept pre-submission inquiries

- Our selector tool helps you to find the most relevant journal

- We provide round the clock customer support

- Convenient online submission

- Thorough peer review

- Inclusion in PubMed and all major indexing services

- Maximum visibility for your research

Submit your manuscript at www.biomedcentral.com/submit
Biomed Central 